\title{
Nerol Attenuates Ouabain-Induced Arrhythmias
}

\author{
José Evaldo Rodrigues de Menezes-Filho, ${ }^{1}$ Diego Santos de Souza, ${ }^{1}$ Artur Santos-Miranda, ${ }^{2}$ \\ Valeska Moraes Cabral, ${ }^{1}$ José Nilson Andrade Santos, ${ }^{1}$ Jader dos Santos Cruz, ${ }^{2}$ \\ Andreza Melo de Araujo, ${ }^{1}$ and Carla Maria Lins de Vasconcelos $\mathbb{1}^{1}$ \\ ${ }^{1}$ Laboratory of Heart Biophysics, Department of Physiology, Federal University of Sergipe, São Cristóvão, Brazil
${ }^{2}$ Excitable Membranes Laboratory, Department of Biochemistry and Immunology, Federal University of Minas Gerais,
Belo Horizonte, Brazil \\ Correspondence should be addressed to Carla Maria Lins de Vasconcelos; carlamlv@hotmail.com
}

Received 28 September 2018; Revised 24 January 2019; Accepted 7 February 2019; Published 7 March 2019

Academic Editor: Shuang-En Chuang

Copyright (c) 2019 José Evaldo Rodrigues de Menezes-Filho et al. This is an open access article distributed under the Creative Commons Attribution License, which permits unrestricted use, distribution, and reproduction in any medium, provided the original work is properly cited.

\begin{abstract}
Nerol $\left(\mathrm{C}_{10} \mathrm{H}_{18} \mathrm{O}\right)$ is a monoterpene found in many essential oils, such as lemon balm and hop. In this study, we explored the contractile and electrophysiological properties of nerol and demonstrated its antiarrhythmic effects in guinea pig heart preparation. Nerol effects were evaluated on atrial and ventricular tissue contractility, electrocardiogram (ECG), voltage-dependent $\mathrm{L}$-type Ca ${ }^{2+}$ current $\left(\mathrm{I}_{\mathrm{C}, \mathrm{L}}\right)$, and ouabain-triggered arrhythmias. Overall our results revealed that by increasing concentrations of nerol (from 0.001 to $30 \mathrm{mM}$ ) there was a significant decrease in left atrium contractile force. This effect was completely and rapidly reversible after washing out ( $2 \mathrm{~min}$ ). Nerol (at $3 \mathrm{mM}$ concentration) decreased the left atrium positive inotropic response evoked by adding up $\mathrm{CaCl}_{2}$ in the extracellular medium. Interestingly, when using a lower concentration of nerol $(30 \mu \mathrm{M})$, it was not possible to clearly observe any significant ECG signal alterations but a small reduction of ventricular contractility was observed. In addition, $300 \mu \mathrm{M}$ nerol promoted a significant decrease on the cardiac rate and contractility. Important to note is the fact that in isolated cardiomyocytes, peak $\mathrm{I}_{\mathrm{Ca}, \mathrm{L}}$ was reduced by $58.9 \pm 6.31 \%$ after perfusing $300 \mu \mathrm{M}$ nerol $(\mathrm{n}=7, \mathrm{p}<0.05)$. Nerol, at 30 and $300 \mu \mathrm{M}$, delayed the time of onset of ouabain-triggered arrhythmias and provoked a decrease in the diastolic tension induced by the presence of ouabain $(50 \mu \mathrm{M})$. Furthermore, nerol preincubation significantly attenuated arrhythmia severity index without changes in the positive inotropism elicited by ouabain exposure. Taken all together, we may be able to conclude that nerol primarily by reducing $\mathrm{Ca}^{2+}$ influx through L-type $\mathrm{Ca}^{2+}$ channel blockade lessened the severity of ouabain-triggered arrhythmias in mammalian heart.
\end{abstract}

\section{Introduction}

Cardiac arrhythmia is caused by changes in the coordinated electrical activity of the heart and is surely among the leading causes of sudden death in the modern world $[1,2]$. Arrhythmias are generally divided into two major types: (1) abnormalities in impulse generation and (2) conduction disturbances [3]. Reductions in repolarizing outward $\mathrm{K}^{+}$currents and/or augments in depolarizing inward $\mathrm{Na}^{+}$or $\mathrm{Ca}^{2+}$ currents can lead to distinct types of cardiac arrhythmias. Cardiac myocytes exhibit an exquisite dynamic control of intracellular $\mathrm{Ca}^{2+}$ homeostasis. Perturbations in this control process have been recognized as a major contributor to lifethreatening ventricular arrhythmias [4]. In this very aspect the model of arrhythmias induced by exposure of heart tissue to ouabain (which is per se a natural product) is an excellent and straightforward approach for the study of the putative antiarrhythmic activity of natural products. Mechanistically, ouabain-triggered arrhythmias is based on disturbances in the intracellular $\mathrm{Ca}^{2+}$ handling, overload of $\mathrm{Ca}^{2+}$, and unbalance of $\mathrm{Na}^{+} / \mathrm{Ca}^{2+}$ exchanger activity (NCX) [5]. Recent studies have reported that cardiac hypertrophy and heart failure may be associated with increased arrhythmogenic risk by the enhanced NCX activity [6,7].

Terpenes complain about a large variety of plant-derived substances. Several terpene compounds in the essential oils are monoterpenes and sesquiterpenes [8]. Chemically, monoterpenes are generally characterized by having $10 \mathrm{car}$ bon atoms linked together and two isoprene units [9]. 
Nerol $\left(\mathrm{C}_{10} \mathrm{H}_{18} \mathrm{O}\right)$ is a monoterpene found in many essential oils [10]. It was originally isolated from the oil of neroli, an oil similar in scent to bergamot oil, which produced orange blossom bergamot (Citrus aurantium var. Loved or Bergamia) and is widely used in the production of perfumes [10]. Nerol is the cis-isomer of geraniol [11].

Neroli essential oil, containing nerol in its composition, is considered one of the most important aromatics for aromatherapy treatment of heart palpitations, anxiety, and depression resulting from stress and anxiety [12]. It is also effective in diminishing the amplitude of heart muscle contraction, thus benefiting people who suffer from palpitations or coronary artery spasm [13, 14]. Evidence pointed out that neroli essential oil is used in aromatherapy to treat heart palpitations, therefore suggesting its putative effect on the mechanical and/or electrical features of the mammalian myocardium. However, the precise mechanism of action and which compound would be the main responsible remained elusive. The aim of the current study was to investigate the possible effects of nerol on electrical and mechanical activities, and whether it exerts protective effects on ouabaintriggered cardiac arrhythmias in an ex vivo model. We, then, hypothesized that nerol could prevent cardiac arrhythmias by modulating $\mathrm{Ca}^{2+}$ current and stabilizing intracellular $\mathrm{Ca}^{2+}$ homeostasis. In order to test this hypothesis, nerol was administered in isolated mammalian heart preparations and cardiomyocytes.

\section{Materials and Methods}

2.1. Animals. To evaluate the effects of nerol on cardiac contractility and on electrocardiogram waveform of intact mammalian heart, experiments were designed and performed using male guinea pigs (Cavia porcellus). This investigation was approved by the local Animal Research Ethics Committee of the Federal University of Sergipe, Brazil (Protocol No. 28/12).

\subsection{Measurement of Contractility in Guinea Pig Left Atrium.} Guinea pigs were sacrificed by decapitation and hearts were removed and isolated left atrium mounted vertically in an organ baths containing Tyrode's solution of the following composition (mM): $\mathrm{NaCl} 120, \mathrm{KCl} 2.7, \mathrm{MgCl}_{2}$ 0.9, $\mathrm{NaHCO}_{3}$ 11.9, $\mathrm{CaCl}_{2}$ 1.37, glucose 5.5, $\mathrm{NaH}_{2} \mathrm{PO}_{4} 0.4, \mathrm{pH}$ 7.4. The atria preparations were subsequently connected to Grass FI'-03 (Grass Instruments, USA) force displacement transducers to record changes in atrial contractile force. Each muscle was stretched to the length at which contractile force was maximal (1.0 gf). The atria were electrically paced at $1 \mathrm{~Hz}$ with pulses of $1.5 \mathrm{~ms}$ duration and stimulated by $70 \mathrm{~V}$ pulses. All preparations were allowed to equilibrate for $30 \mathrm{~min}$ until complete mechanical stabilization had been achieved. Nerol ( $\geq 97 \%$, Lot\#MKBP7755V, Sigma-aldrich) was freshly solubilized in $0.5 \%$ DMSO and cumulatively added to bath chambers. After each observation, muscles were washed several times and allowed to recover for 30 minutes until their mechanical function completely returned to control values. DMSO at this concentration did not show any significant effect on the variables measured (data not shown, $n=5$ ).
2.3. Effect of Nerol on $\mathrm{Ca}^{2+}$ Influx. A pharmacological approach was used to investigate the effect of nerol on $\mathrm{Ca}^{2+}$ influx. Indeed, concentration-response curves for extracellular $\mathrm{CaCl}_{2}(0.5-8 \mathrm{mM})$ were obtained before and after preincubating with nerol $(300 \mu \mathrm{M})$ during $15 \mathrm{~min}$. The results were expressed as percentage of the maximum atrial contractile attained response to a given extracellular $\mathrm{CaCl}_{2}$ concentration.

\subsection{Electrocardiogram Waveform and Left Ventricular Pres-} sure Measurements. Guinea pigs were heparinized (1,000 IU, i.p.) and the hearts excised via an anterolateral thoracotomy and immediately immersed in Tyrode's solution. The aorta was quickly cannulated to the Langendorff apparatus, and the heart was retrogradely perfused $(8 \mathrm{~mL} / \mathrm{min})$ using a peristaltic pump (Milan Peristaltic Pump, Curitiba, Brazil). Tyrode's solution was maintained at $34.0 \pm 1^{\circ} \mathrm{C}$ (HAAKE F3, Berlin, Germany) and gassed with a mixture of $95 \% \mathrm{O}_{2}$ and $5 \% \mathrm{CO}_{2}(\mathrm{pH} \sim 7.4)$. To measure the Left Ventricular Developed Pressure (LVDP), a water filled latex balloon was placed into the left ventricular cavity and connected to a pressure transducer (FE221, Bridge Amp, ADInstruments, Colorado, USA). The system was calibrated using a column of mercury $15 \mathrm{cmHg}$. ECG waveform was recorded through three electrodes $(\mathrm{Ag} / \mathrm{AgCl} / \mathrm{NaCl} 1 \mathrm{M})$ that were placed near the heart surface to detect and record macroscopic electrical signals. All signals were amplified and digitalized sampling frequency of $400 \mathrm{~Hz}$ (PowerLab 4/35, ADInstruments, Colorado, USA) and stored in a computer (PC-compatible) for offline processing using dedicated software (LabChart 8 Pro, ADInstruments, Colorado, USA). To measure ECG parameters, such as the PR interval, QT interval, and the duration of the QRS complex, the heart was electrically stimulated by Grass stimulus isolation unit (SIU5) connected to a Grass S48 stimulator (100 V, $1 \mathrm{~Hz}, 2 \mathrm{~ms}$ pulse duration). For QT correction, Bazett's formula was used $(\mathrm{QTc}=\mathrm{QT} / \sqrt{ } \mathrm{RR})$. To measure heart rate (beats per minute), the isolated heart was allowed to beat spontaneously following sinus rhythm.

\subsection{Effects of Nerol on the L-Type $\mathrm{Ca}^{2+}$ Channel in Isolated} Ventricular Cardiomyocytes. Using an EPC-9.2 patch-clamp amplifier (HEKA Electronics, Rheinland-Pfalz, Germany) we recorded voltage-dependent L-type $\mathrm{Ca}^{2+}$ current $\left(\mathrm{I}_{\mathrm{Ca}, \mathrm{L}}\right)$ in the whole-cell voltage-clamp configuration of the patchclamp technique $[15,16]$. Ventricular cardiomyocytes were isolated from guinea pig heart by enzymatic digestion as described by Shioya [17] with minor modifications (reduction of enzyme time in the first and second tubes for $6 \mathrm{~min}$ ). The recording electrodes had uncompensated tip resistances of 1-3 M $\Omega$. Cardiomyocytes presenting a series resistance (Rs) above $10 \mathrm{M} \Omega$ were promptly discarded from the analysis. The composition of pipette solution was as follows (in $\mathrm{mM}$ ): 120 CsCl, 20 TEACl, $5 \mathrm{NaCl}, 10 \mathrm{HEPES}$ and 10 EGTA, and $1 \mathrm{MgCl}_{2}$ ( $\mathrm{pH}$ was set to 7.2 using $\mathrm{CsOH}$ ) and external solution was as follows (in mM): $150 \mathrm{TEACl}, 0.5 \mathrm{MgCl}_{2}, 1.8 \mathrm{CaCl}_{2}, 10 \mathrm{HEPES}$, and 11 glucose ( $\mathrm{pH} 7.4$ set using $\mathrm{TEA}(\mathrm{OH}))$. The holding potential was set at $-80 \mathrm{mV}$ and prepulses were elicited from $-80 \mathrm{mV}$ to $-40 \mathrm{mV}$ for $50 \mathrm{~ms}$ (every $10 \mathrm{~s}$ ) to inactivate any 


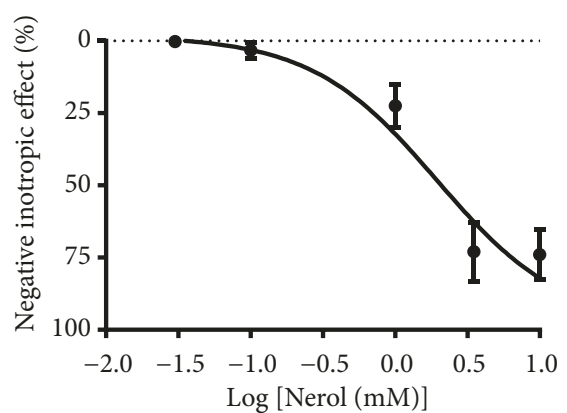

(a)

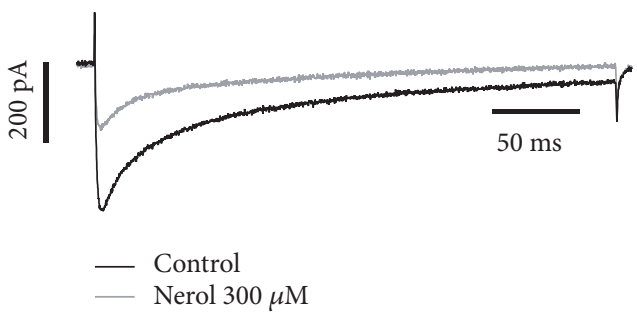

(c)

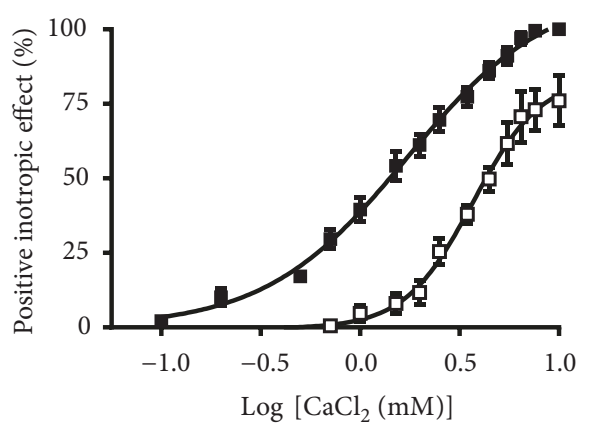

- Control

$\rightarrow$ Nerol $3 \mathrm{mM}$

(b)

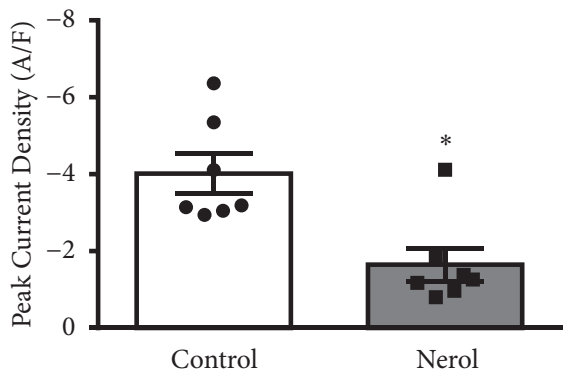

(d)

FIGURE 1: Effects of nerol on the contractility of guinea pig left atrium and on the calcium influx. (a) Concentration-response curve for the negative inotropic effect of nerol $\left(\mathrm{EC}_{50}=1.94 \pm 0.2 \mathrm{mM}, \mathrm{n}=5\right.$ ). (b) Concentration-response curves of $\mathrm{CaCl}_{2}$ in control situation and in the presence of nerol $(n=5)$. (c) Representative recording showing the L-type calcium currents $\left(\mathrm{I}_{\mathrm{Ca}, \mathrm{L}}\right)$ in control and $300 \mu \mathrm{M}$ nerol. $(\mathrm{d})$ Average effect of nerol on the $\mathrm{I}_{\mathrm{Ca}, \mathrm{L}}$ density $(\mathrm{n}=7, * \mathrm{p}<0.05)$. Data are represented as mean \pm SEM. Paired Student's $t$-test.

remnant $\mathrm{Na}^{+}$and/or T-type $\mathrm{Ca}^{2+}$ channels [16]. Then, it was applied a test pulse to $0 \mathrm{mV}$ during $300 \mathrm{~ms}$ to directly measure $\mathrm{I}_{\mathrm{Ca}, \mathrm{L}}$.

2.6. Effects of Nerol on the Ouabain-Triggered Arrhythmias. Antiarrhythmic effect of nerol on the cardiac arrhythmias induced by ouabain was evaluated in spontaneously beating isolated heart $[18,19]$. After stabilization $(30 \mathrm{~min})$, the hearts were perfused with ouabain $(50 \mu \mathrm{M},[20])$ for $10 \mathrm{~min}$. The hearts were preincubated with nerol (either 30 or $300 \mu \mathrm{M}) 10 \mathrm{~min}$ before ouabain or nifedipine $(0.35 \mu \mathrm{M})$. Parameters investigated were maximal inotropic effect, maximal tonotropic effect, inotropic response rate $(\mathrm{dP} / \mathrm{dt})$, and onset time of arrhythmias evoked by ouabain. Furthermore, we investigated the occurrence of subtypes of ventricular arrhythmias, such as ventricular premature beats (VPB), ventricular tachycardia (VT), and/or ventricular fibrillation (VF). Arrhythmia scores were evaluated by subtypes and arbitrarily classified as previously validated by Curtis and Walker [21]. Then, The experiment was then divided into 5 intervals of 2 minutes and, depending on the type of arrhythmia, was assigned a scrore. Episodes of $\mathrm{VPB}<10$ events $/ 2 \mathrm{~min}$ were classified as score 0 and $>10$ events $/ 2 \mathrm{~min}$ scored 1; episodes of VT $<30 \mathrm{~s}$ were 2 and $>30 \mathrm{~s}$ were 3; episodes of VF $<30 \mathrm{~s}$ scored as 4 and $>30 \mathrm{~s}$ as 5 .
2.7. Statistical Analysis. Results were expressed as mean \pm SEM. Statistical significance was determined by using Student's $t$-test or one-way ANOVA followed by Tukey's post hoc test and Chi-squared test. $\mathrm{p}<0.05$ was considered significant.

\section{Results}

Our initial series of experiments were aimed at determining the baseline effects of nerol on cardiac contractility. As shown in Figure 1, nerol decreased contractile force of the isolated guinea pig atria (Figure $1(a), n=5$ ). This effect was dependent on nerol concentration (Figure 1(a), $\mathrm{EC}_{50}=1.94 \pm 0.2 \mathrm{mM}$, $\mathrm{n}=5$ ) and was almost completely reversible upon washout recovering up to $83.9 \pm 4.1 \%$.

Because the development of contractile force is known to rely on $\mathrm{Ca}^{2+}$ influx into the sarcoplasm from the extracellular milieu, we investigated whether nerol prevent $\mathrm{Ca}^{2+}$ activated force production. As depicted in Figure 1(b), the positive inotropic maximal response produced by increasing cumulatively extracellular $\mathrm{Ca}^{2+}$ was significantly diminished by nearly $25 \%$ by $3 \mathrm{mM}$ nerol. Interestingly, $\mathrm{EC}_{50}$ which is a measure of responsiveness to $\mathrm{Ca}^{2+}$ was significantly altered by the presence of nerol (Figure 1(b), 2.2-fold increase). The $\mathrm{EC}_{50}$ of $\mathrm{CaCl}_{2}$ in control conditions was $1.7 \pm 0.4 \mathrm{mM}$ (Figure 1(b), closed squares, $\mathrm{n}=8$ ) and in the presence of nerol was $3.7 \pm 0.5 \mathrm{mM}$ (Figure 1(b), Open squares, $\mathrm{n}=5$, 


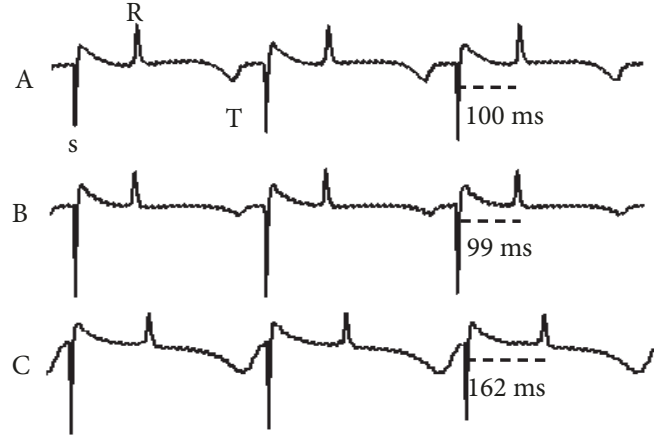

(a)

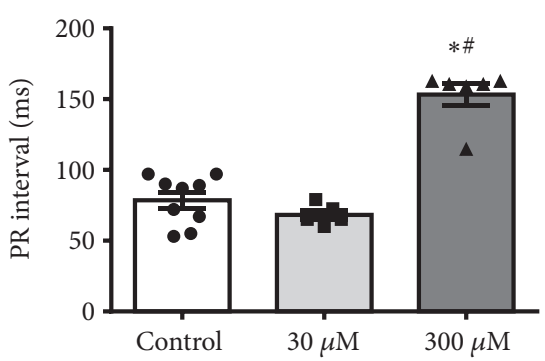

(c)

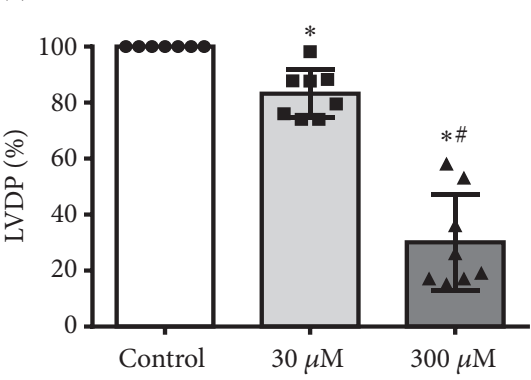

(f)

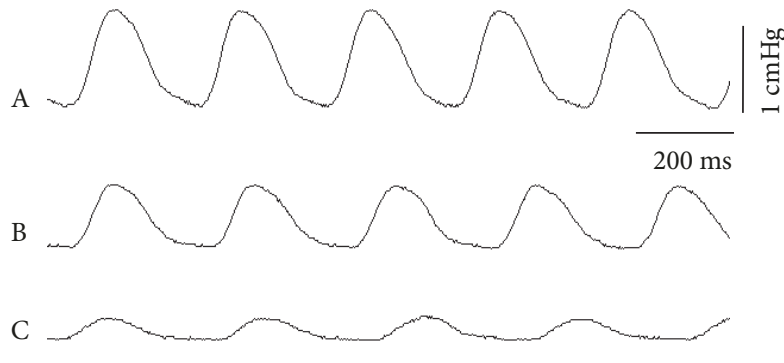

(b)

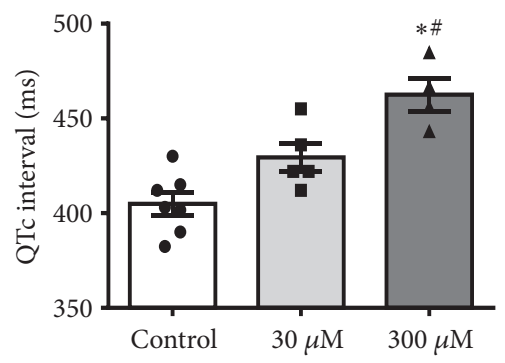

(d)

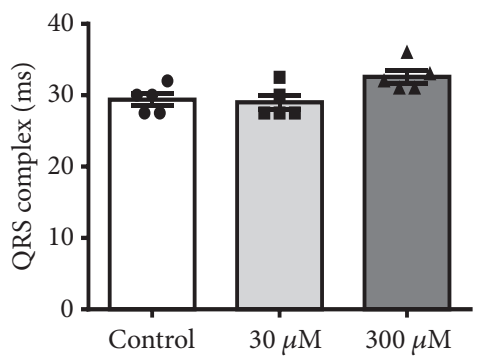

(e)

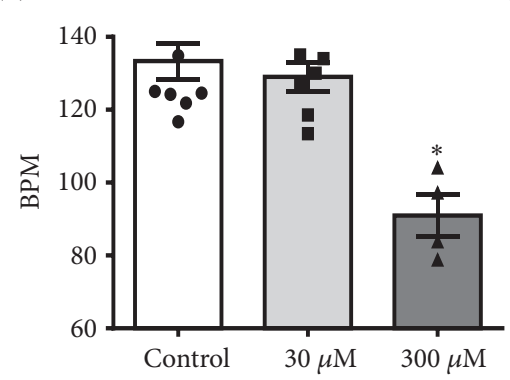

(g)

FIGURE 2: Effect of nerol on the electrocardiographic parameters and left ventricular developed pressure (LVDP) in guinea pig isolated heart. (a) Representative traces of ECG in control (A), $30 \mu \mathrm{M}(\mathrm{B})$, and $300 \mu \mathrm{M}$ nerol (C). (b) Representative traces of LVDP in control (A), after 10 min of perfusion with $30 \mu \mathrm{M}$ (B) and $300 \mu \mathrm{M}$ (C) nerol. (c) Effect of nerol on the PR interval, (d) QTc interval, (e) QRS complex duration, (f) LVDP, and (g) heart rate (BPM). Data are represented as means \pm SEM $(\mathrm{n}=4-9, * \mathrm{p}<0.05$ versus control, \#p<0.05 versus $30 \mu \mathrm{M}$ nerol). One-way ANOVA followed by Tukey's post hoc test.

$\mathrm{p}<0.05)$. This enhancement of the $\mathrm{EC}_{50}$ of $\mathrm{Ca}^{2+}$ activation could be indicative of a reduction in $\mathrm{Ca}^{2+}$ entry.

We next considered whether nerol would inhibit Ltype $\mathrm{Ca}^{2+}$ channels. Accordingly, L-type $\mathrm{Ca}^{2+}$ current $\left(\mathrm{I}_{\mathrm{Ca}, \mathrm{L}}\right)$ was measured using whole-cell voltage-clamp technique in isolated guinea pig ventricular cardiomyocytes. As illustrated in Figure 1(c), $300 \mu \mathrm{M}$ nerol caused a significant decreased in peak $\mathrm{I}_{\mathrm{Ca}, \mathrm{L}}$. After 1.15 minutes of superfusion with nerol, a decrease of peak $\mathrm{I}_{\mathrm{Ca}, \mathrm{L}}$ from $-4.0 \pm 0.5 \mathrm{~A} / \mathrm{F}$ to $-1.6 \pm 0.4 \mathrm{~A} / \mathrm{F}$ was observed. The average decrease of peak $\mathrm{I}_{\mathrm{Ca}, \mathrm{L}}$ induced by nerol was $58.9 \pm 6.3 \%$ (Figure $1(\mathrm{~d}), \mathrm{p}<0.05, \mathrm{n}=7$ ). These results indicate that $\mathrm{Ca}^{2+}$ influx was reduced by nerol through inhibition of L-type $\mathrm{Ca}^{2+}$ channels in guinea pig cardiomyocytes.

We also investigated the effects of nerol in isolated heart recording simultaneously electrocardiogram (ECG, Figure 2(a)) and left ventricular developed pressure (LVDP, Figure 2(b)). ECG was recorded in electrically stimulated heart to permit measurement of ECG intervals and in spontaneously beating heart to evaluate heart rate. Figure 2(a) displays typical traces of ECG in control (Trace a) and during $30 \mu \mathrm{M}$ (Trace b) and $300 \mu \mathrm{M}$ nerol perfusion (Trace c). The results showed that $30 \mu \mathrm{M}$ nerol did not change PR interval (Figure 2(c)), QTc interval (Figure 2(d)), QRS complex duration (Figure 2(e)), and heart rate (Figure $2(\mathrm{~g})$ ). Important to note is the fact that at this concentration nerol decreased LVDP by only 17\% (Figure 2(f)).

On the other hand, when using higher concentration, nerol $(300 \mu \mathrm{M})$ evoked an increase of PR interval (from $78.5 \pm$ $5.7 \mathrm{~ms}$ to $153.2 \pm 7.7 \mathrm{~ms}, \mathrm{p}<0.05$, Figure $2(\mathrm{c}))$ and QTc interval (from $404.9 \pm 6.0 \mathrm{~ms}$ to $462.6 \pm 8.8 \mathrm{~ms}, \mathrm{p}<0.05$, Figure $2(\mathrm{~d})$ ) without altering QRS complex duration (Figure 2(e)). Furthermore, this concentration promoted reduction of LVDP to $30.1 \pm 6.0 \%$ (Figure 2(f)) and heart rate (from $133.4 \pm 4.9 \mathrm{bpm}$ to $90.9 \pm 5.8 \mathrm{bpm}, \mathrm{p}<0.05$, Figure $2(\mathrm{~g})$ ). 


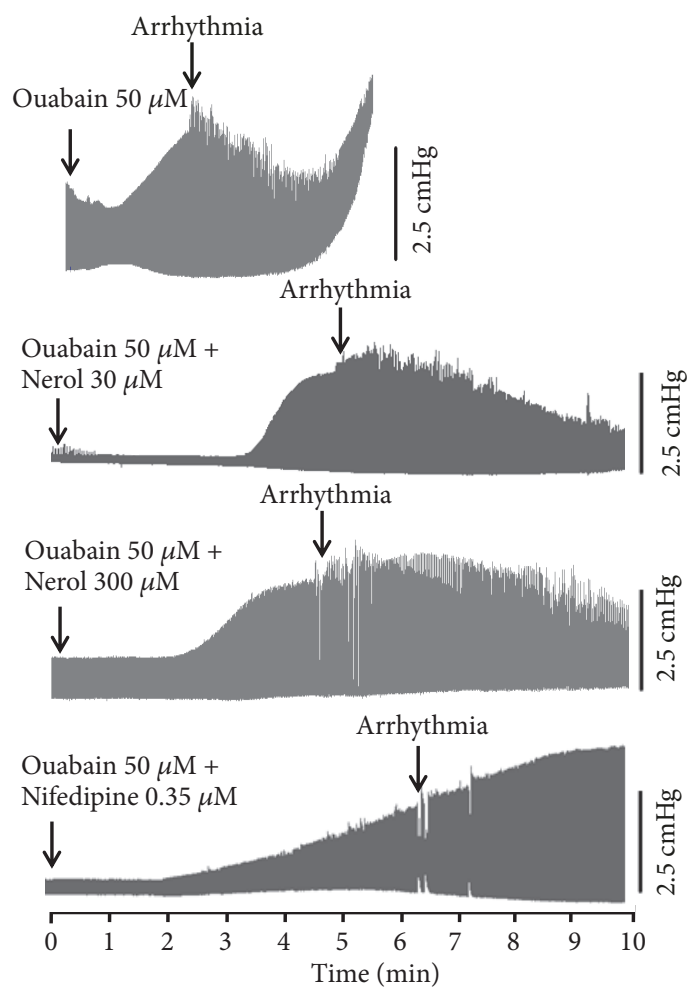

(a)

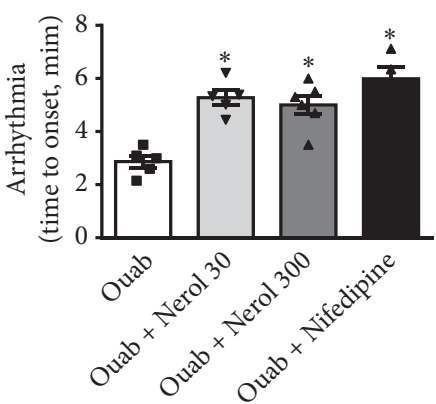

(b)

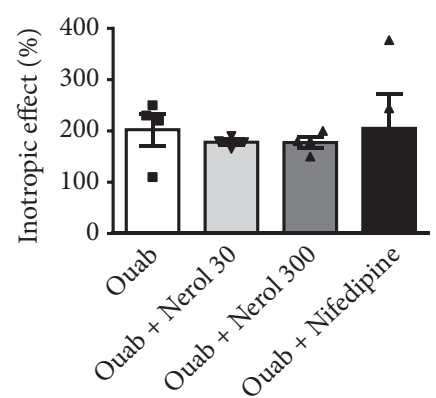

(c)

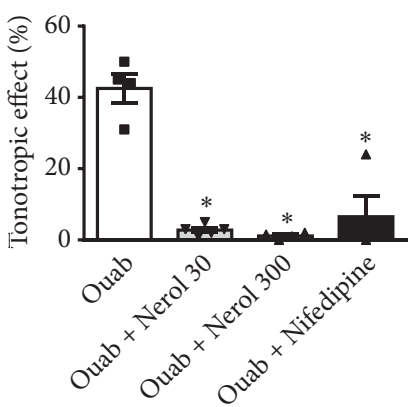

(d)

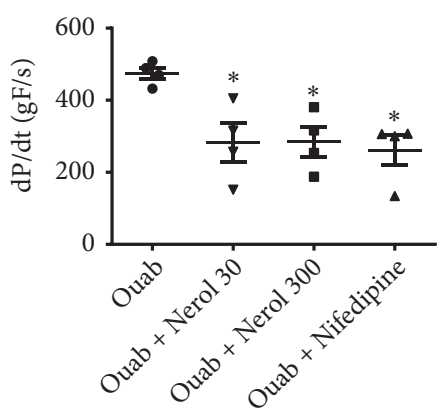

(e)

FIGURE 3: Protective effects of nerol on ouabain-induced arrhythmias in guinea pig hearts. (a) Representative recording of effects of ouabain (Ouab, $50 \mu \mathrm{M}$ ) on left ventricular developed pressure (LVDP, Top panel), nerol (30 and $300 \mu \mathrm{M})+$ ouabain (middle), and nifedipine (0.35 $\mu \mathrm{M})+$ ouabain (botton). Summary of effects of nerol or nifedipine preincubation on the onset time of arrhythmia (b), inotropic response (c), tonotropic effect $(\mathrm{d})$, and inotropic response rate $(\mathrm{dP} / \mathrm{dt})$ induced by ouabain $(\mathrm{e})$, respectively. Data are represented as means \pm SEM $(\mathrm{n}=5-$ $6, * \mathrm{p}<0.05$ versus Ouab). One-way ANOVA followed was by Tukey’s post hoc test.

As L-type calcium channel blocker drugs are used as cardiac antiarrhythmics we reasoned that nerol could be of interest to study possible antiarrhythmic properties. The protective effects of nerol on ouabain-induced arrhythmias were examined in guinea pig hearts. Figure 3(a) shows representative recording of ouabain $(50 \mu \mathrm{M})$ effects on LVDP (Top panel). As one would expect ouabain elicited a progressive increase in ventricular inotropic response. The systolic contractions became irregular (arrhythmic events) after $3.04 \pm$ $0.25 \mathrm{~min}$ (onset of arrhythmia, $\mathrm{n}=6$ ). After this period, contractile force amplitude significantly decreased; arrhythmia then became severe and associated with strong diastolic contracture (tonotropic effect). Finally, cardiac arrest occurred at the end of $5 \mathrm{~min}$. However, when ouabain $(50 \mu \mathrm{M})$ was added $15 \mathrm{~min}$ after the perfusion of 30 or $300 \mu \mathrm{M}$ nerol, the onset time of arrhythmia considerably delayed to $5.3 \pm$ $0.28 \min (\mathrm{p}<0.05, \mathrm{n}=6)$ and $5.00 \pm 0.35 \min (\mathrm{p}<0.05, \mathrm{n}=6)$ (Figure 3(a), middle panel), respectively. We took advantage of a well-known L-type $\mathrm{Ca}^{2+}$ channel inhibitor, nifedipine, used at $0.35 \mu \mathrm{M}$ to match a similar L-type $\mathrm{Ca}^{2+}$ current blockade as observed with nerol at $300 \mu \mathrm{M}$. Therefore, this concentration of nifedipine would cause about $60 \%$ reduction of the L-type $\mathrm{Ca}^{2+}$ current [22]. This maneuver was done in order to evaluate the involvement of similar reduction of L-type $\mathrm{Ca}^{2+}$ current on antiarrhythmic effect (Figure 3(a), bottom panel). Importantly, nifedipine promoted a delay of 
$5.90 \pm 0.50 \mathrm{~min}(\mathrm{n}=4)$ on the onset time of ouabain-triggered arrhythmia which is strikingly similar to that provoked by nerol. Figures 3(b), 3(c), 3(d), and 3(e) summarize the effects of nerol or nifedipine preincubation on the onset time of arrhythmia, inotropic response, tonotropic effect, and inotropic response rate $(\mathrm{dP} / \mathrm{dt})$ induced by ouabain, respectively. We conclude that nerol can mimic the nifedipine in abolition of responses induced by ouabain.

The data above are consistent with the idea of proposing nerol as an antiarrhythmogenic agent. The remaining experiments aim to clarify this possibility further. By analyzing electrocardiographic tracings, it was possible to classify the major types of arrhythmic events induced by ouabain. As demonstrated in Figure 4(a), $50 \mu \mathrm{M}$ ouabain evoked the occurrence of ventricular premature beatings (VPB), ventricular tachycardia (VT), and ventricular fibrillation (VF). The severity score of arrhythmias increased from $2.5 \pm 0.6$ a.u (control) to $43.6 \pm 4.5$ a.u after exposure to ouabain (Figure $4(\mathrm{~b}), * \mathrm{p}$ $<0.05)$. Notably, preincubation with 30 and $300 \mu \mathrm{M}$ nerol decreased significantly the severity score of arrhythmia to 6.6 \pm 1.8 a.u and $12.2 \pm 3.8$ a.u, respectively (Figure $4(\mathrm{~b}), \mathrm{p}<$ 0.05). Figure 4(c) shows that in control conditions the VPB is by far the prevalent (100\%) form of arrhythmia whereas when hearts were perfused with ouabain more severe types of arrhythmias were observed such as VT (50\% occurrence) and VF (42\% occurrence). Importantly, preincubation with nerol (30 and $300 \mu \mathrm{M}$ ) attenuated the development of more severe arrhythmias as VT and VF being the ventricular arrhythmia; VPB was more prevalent. Ouabain, by itself, provoked an increase of PRi (54\%, Figure 4(d)) and QRS complex duration $(21 \%$, Figure $4(\mathrm{e}))$ associated with reduction of QTc $(30 \%$, Figure 4(f)). Noticing that those ECG alterations are reported to be typical of digitalis toxicity $[23,24]$. To our surprise, the increase of PRi and QTi and alterations previously described in ECG parameters were prevented by preincubation with 30 and $300 \mu \mathrm{M}$ nerol.

\section{Discussion}

The development of cardiac arrhythmias result from a number of different causes from genetic mutations to acquired cardiac diseases. Unequivocally they constitute a major cause of sudden death in the world $[25,26]$. In the past few decades, it has become clear that cardiac arrhythmogenesis is related to ion channel dysfunctions and uncontrolled intracellular $\mathrm{Ca}^{2+}$ dynamics. It is, therefore, imperative to motivate studies looking for pharmacological agents that present cardioprotective effects against cardiac arrhythmias $[5,27,28]$.

In this study, we used a combination of different approaches to investigate the mechanisms by which nerol acts controlling $\mathrm{Ca}^{2+}$ influx and the subsequent impact on ouabain-triggered arrhythmias. Our major findings are as follows: (a) nerol in lower concentrations $(30 \mu \mathrm{M})$ promotes small reduction of contractile response without alter ECG parameters and pacemaker activity; (b) nerol at $300 \mu \mathrm{M}$ inhibits L-type $\mathrm{Ca}^{2+}$ current by $60 \%$ and affect ECG, heart rate, and left ventricular performance; (c) nerol, in both concentrations investigated, suppressed ouabain-triggered arrhythmias; and (d) nerol protects the heart against ventricular tachycardia and ventricular fibrillation. These findings, altogether, are consistent with the idea of proposing nerol as an antiarrhythmogenic agent.

To our surprise, there are fewer studies using nerol (trans isomer) than geraniol (cis isomer). Nonetheless, there are numerous reports on the antitumoral [29], antioxidant [30], and anti-inflammatory properties of these monoterpenes. Specifically in the case of nerol limited information is available on its effect on cardiac myocytes [31].

In mammalian heart, several routes can lead to reduction of cardiac contractility and as it is well known, intracellular $\mathrm{Ca}^{2+}$ is central to regulate contractile force in the heart. In fact, our results show that nerol decreases $\mathrm{Ca}^{2+}$ entry into cardiomyocytes through inhibition of L-type $\mathrm{Ca}^{2+}$ channels reducing contractile force. Important to note at this point that nerol at $300 \mu \mathrm{M}$ mediates $70 \%$ of reduction on contractile force and $60 \%$ blockade of L-type $\mathrm{Ca}^{2+}$ current. This allowed us to study further to better characterize the pharmacological effects of nerol. Furthermore, in this concentration, a decrease in pacemaker activity (31\%) associated with increase of both PRi and QTi at baseline conditions was observed. These results were somehow expected because previously Menezes-Filho et al. [9] reported that geraniol (a nerol geometric isomer) elicited PR and QT interval increase, reduced pacemaker activity $(\sim 16 \%)$, and markedly reduced LVDP $(\sim 83 \%)$. A novel finding in this study is that nerol, in lower concentration, did not affect pacemaker activity or ECG major parameters but promoted a small reduction on LVDP (17\%).

Stability of intracellular $\mathrm{Ca}^{2+}$ dynamics is intimately connected to $\mathrm{I}_{\mathrm{Ca}, \mathrm{L}}, \mathrm{Na}^{+} / \mathrm{Ca}^{2+}$ exchange (NCX), Sarco(Endo)plasmic Reticulum $\mathrm{Ca}^{2+}$-ATPase (SERCA2a), and RyR2 in cardiomyocytes, being the key regulators of cardiac contractility. However, any source of instability can provoke arrhythmias [32]. Arrhythmia as induced by ouabain is originated by several mechanisms. The most accepted starts with $\mathrm{Na}^{+} / \mathrm{K}^{+}$ pump blockade by cardiac glycosides (such as ouabain) which increases $\left[\mathrm{Na}^{+}\right] \mathrm{i}$, which enhances cell contractility by increasing intracellular $\left[\mathrm{Ca}^{2+}\right]$ due to NCX [33]. This may be explained by reduced $\mathrm{Ca}^{2+}$ efflux by the NCX as $\left[\mathrm{Na}^{+}\right]$i rises. In other words, less $\mathrm{Ca}^{2+}$ efflux for a given $\mathrm{Ca}^{2+}$ influx would increase intracellular $\mathrm{Ca}^{2+}$. The increased $\left[\mathrm{Na}^{+}\right] \mathrm{i}$ could also increase $\mathrm{Ca}^{2+}$ influx via reverse-mode of NCX $[34,35]$ producing $\mathrm{Ca}^{2+}$ overload. During $\mathrm{Ca}^{2+}$ overload oscillatory $\mathrm{Ca}^{2+}$ releases from the SR lead to membrane depolarization favoring triggered arrhythmias. To gain more insight into nerol antiarrhythmogenic potential we made use of the ouabain-triggered arrhythmia model in guinea pig.

Our results indicate that tonotropic effect caused by ouabain is completely abolished by nerol or nifedipine suggesting that ouabain-elicited tonotropic effect does depend on $\mathrm{Ca}^{2+}$ influx through L-type $\mathrm{Ca}^{2+}$ channels. We can conclude that nerol interacts with and inhibits L-type $\mathrm{Ca}^{2+}$ channels. Nerol and nifedipine slowed down LVDP rate $(\mathrm{dP} / \mathrm{dt})$ arguing in favor of the notion that L-type 


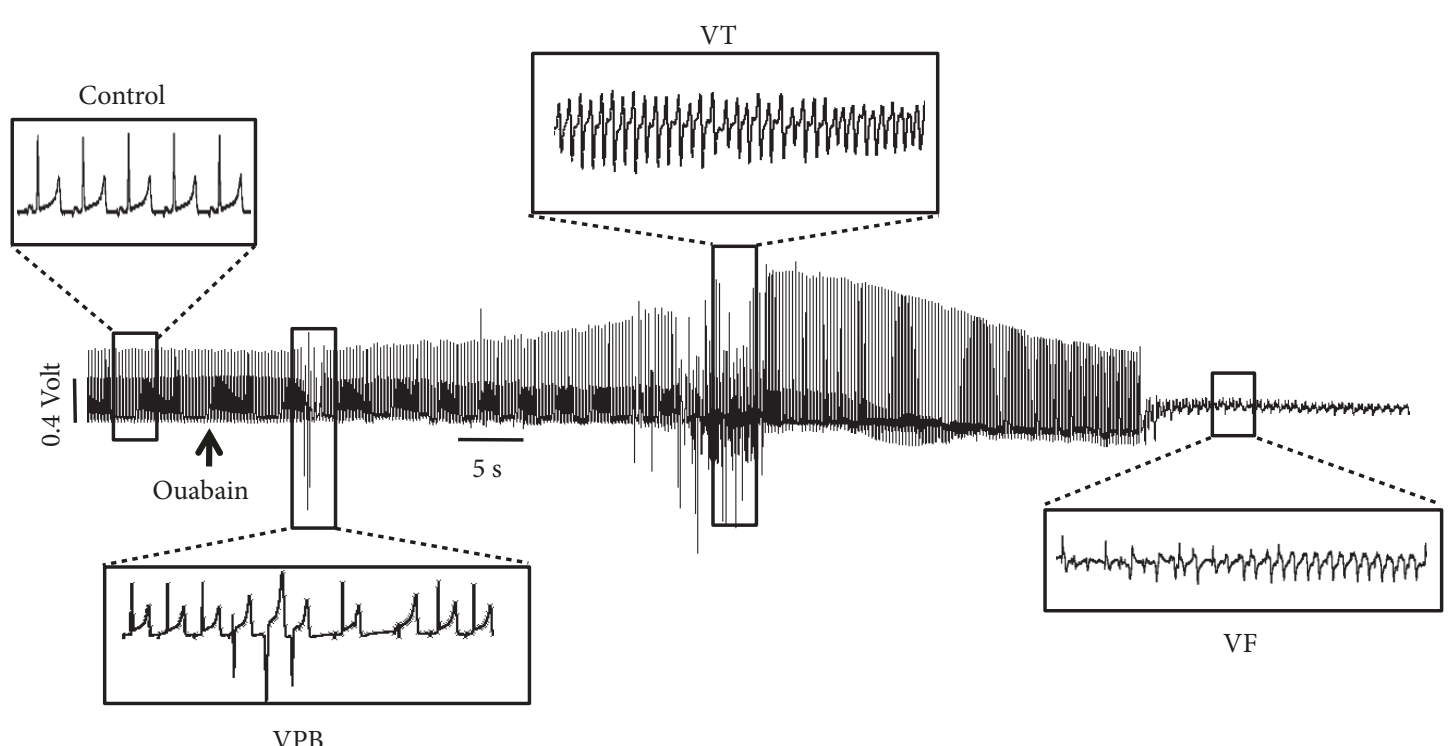

(a)

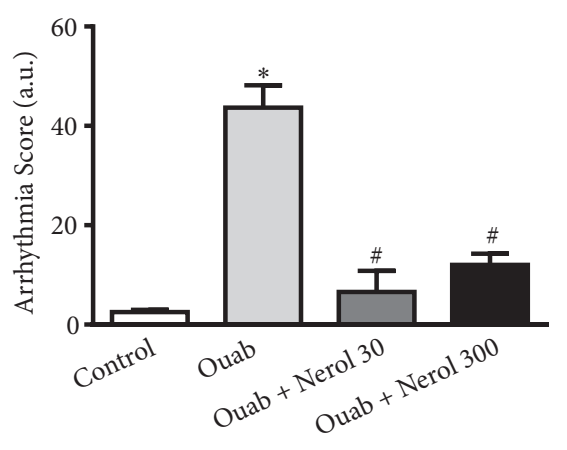

(b)

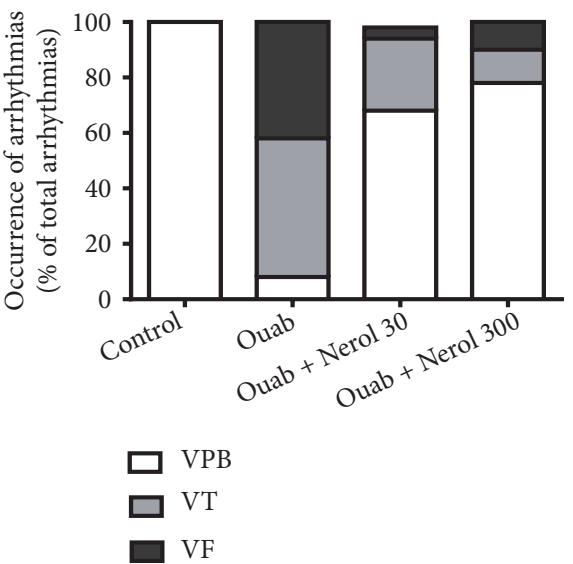

(c)

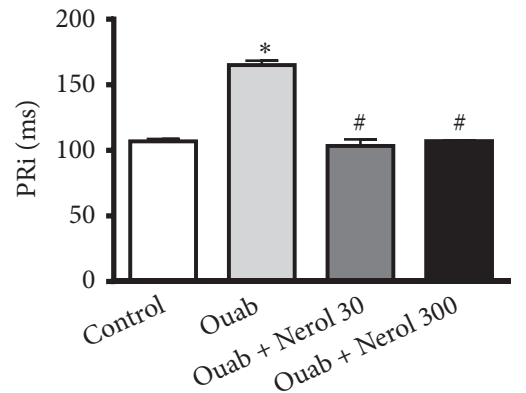

(d)

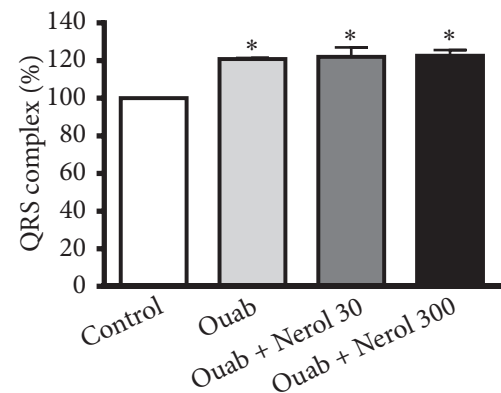

(e)

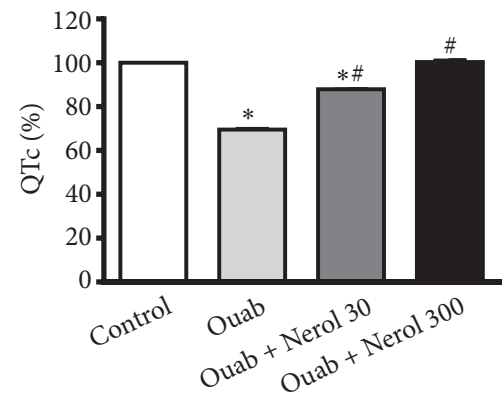

(f)

FIGURE 4: Nerol attenuates cardiac arrhythmias and electrocardiographic (ECG) alterations induced by ouabain. (a) Representative ECG recordings with $50 \mu \mathrm{M}$ ouabain (Ouab) evoking the occurrence of ventricular premature beatings (VPB), ventricular tachycardia (VT), and ventricular fibrillation (VF). (b) Arrhythmias score and (c) occurrence of arrhythmias (VPB, VT, VF). ECG parameters: PR interval (d), QRS complex (e), and QTc interval (f). Data are represented as means \pm SEM ( $n=4-7, * p<0.05$ versus control, \# $<<0.05$ versus ouabain). One-way ANOVA followed by Tukey's post hoc test. Chi-squared test (c).

$\mathrm{Ca}^{2+}$ current is participating on early phase of inotropic response.

Several groups have previously demonstrated that the positive inotropism observed during the exposure to ouabain is mostly related to $\mathrm{Ca}^{2+}$ influx through NCX when intracellular $\left[\mathrm{Na}^{+}\right] \mathrm{i}$ increases as a result of $\mathrm{Na}^{+} / \mathrm{K}^{+}$ATPase inhibition. Nerol at 30 and $300 \mu \mathrm{M}$ delayed the onset time for cardiac arrhythmias but the ouabain-triggered inotropy remained largely intact (see Figure 3(b)). These results suggest that nerol does not affect, directly or indirectly, NCX 
mediated $\mathrm{Ca}^{2+}$ dynamics. Furthermore, nerol decreased the occurrence of more severe arrhythmias such as tachycardia and ventricular fibrillation.

In our study, nerol corrected key adverse effects of ouabain-triggered arrhythmias: it abolished heart diastolic contracture, it recovered electrical activity, and it reduced the propensity to generate arrhythmias. This is the first study to actually demonstrate that, mechanistically, nerol at low concentration can preserve inotropy and the electrical properties of cardiac muscle while at the same time acting as antiarrhythmic agent. Taken all together, nerol may be useful adjunct to digitalis treatment and justifies further investigation.

\section{Limitations}

Small animal models are commonly used in cardiovascular research showing advantages and disadvantages [36]. The present study used guinea pig as a model because its isolated cardiomyocytes' action potential waveform and calcium handling resembles that encountered in human ventricular cardiomyocytes. In accordance with this statement, the effect of ouabain, used to induce arrhythmias, is more pronounced in guinea pigs because of higher relative contribution of NCX (28\%) in removing intracellular calcium during diastole when compared to rats (7\%) [37]. Although the animal model has similarities, we must be cautious in translating the results to humans. As nerol presented antiarrhythmic effects in a very specific model (ouabain-triggered arrhythmias) we intend to continue this investigation using other models to induce cardiac arrhythmias that could be closer to that of humans and therefore establish a more general mechanism to impair arrhythmogenesis.

\section{Data Availability}

The data used to support the findings of this study are available from the corresponding author upon request.

\section{Conflicts of Interest}

The authors declare no conflicts of interest in the present study.

\section{Authors' Contributions}

José Evaldo Rodrigues de Menezes-Filho and Diego Santos de Souza contributed equally to this work.

\section{Acknowledgments}

This study was supported by Conselho Nacional de Desenvolvimento Científico e Tecnológico (CNPq), Coordenação de Aperfeiçoamento de Pessoal de Nível Superior (CAPES), Fundação de Amparo à Pesquisa de Minas Gerais (FAPEMIG), and Fundação de Apoio à Equipe e à Inovação Tecnológica do Estado de Sergipe (FAPITEC/SE). Jader dos Santos Cruz is CNPq research fellow (Project \# 312474/20172). José Evaldo Rodrigues de Menezes-Filho, Diego Santos de
Souza, and Artur Santos-Miranda are recipients of CAPES scholarship.

\section{References}

[1] K. Porthan, M. Viitasalo, L. Toivonen et al., "Predictive value of electrocardiographic T-wave morphology parameters and Twave peak to T-wave end interval for sudden cardiac death in the general population," Circulation: Arrhythmia and Electrophysiology, vol. 6, no. 4, pp. 690-696, 2013.

[2] J. W. Waks, C. M. Sitlani, E. Z. Soliman et al., "Global electric heterogeneity risk score for prediction of sudden cardiac death in the general population: the atherosclerosis risk in communities (ARIC) and cardiovascular health (CHS) studies," Circulation, vol. 133, no. 23, pp. 2222-2234, 2016.

[3] M. Deo, S. H. Weinberg, and P. M. Boyle, "Calcium dynamics and cardiac arrhythmia," Clinical Medicine Insights: Cardiology, vol. 11, p. $117954681773952,2017$.

[4] A. P. Landstrom, D. Dobrev, and X. H. T. Wehrens, "Calcium signaling and cardiac arrhythmias," Circulation Research, vol. 120, no. 12, pp. 1969-1993, 2017.

[5] P. Baumeister and T. A. Quinn, "Altered calcium handling and ventricular arrhythmias in acute ischemia," Clinical Medicine Insights: Cardiology, vol. 10, supplement 1, pp. 61-69, 2016.

[6] K. R. Sipido, V. Bito, G. Antoons, P. G. Volders, and M. A. Vos, "Na/Ca exchange and cardiac ventricular arrhythmias," Annals of the New York Academy of Sciences, vol. 1099, pp. 339-348, 2007.

[7] K. R. Sipido, P. G. A. Volders, M. Schoenmakers, S. H. Marieke De Groot, F. Verdonck, and M. A. Vos, "Role of the $\mathrm{Na} / \mathrm{Ca}$ exchanger in arrhythmias in compensated hypertrophy," Annals of the New York Academy of Sciences, vol. 976, pp. 438-445, 2002.

[8] N. Dudareva, A. Klempien, J. K. Muhlemann, and I. Kaplan, "Biosynthesis, function and metabolic engineering of plant volatile organic compounds," New Phytologist, vol. 198, no. 1, pp. 16-32, 2013.

[9] J. E. R. de Menezes-Filho, A. N. S. Gondim, J. S. Cruz et al., "Geraniol blocks calcium and potassium channels in the mammalian myocardium: useful effects to treat arrhythmias," Basic \& Clinical Pharmacology \& Toxicology, vol. 115, no. 6, pp. 534-544, 2014.

[10] A. E. González-Ramírez, M. E. González-Trujano, S. A. OrozcoSuárez, N. Alvarado-Vásquez, and F. J. López-Muñoz, "Nerol alleviates pathologic markers in the oxazolone-induced colitis model," European Journal of Pharmacology, vol. 776, pp. 81-89, 2016.

[11] J. Tian, Y. Gan, C. Pan et al., "Nerol-induced apoptosis associated with the generation of ROS and $\mathrm{Ca} 2+$ overload in saprotrophic fungus Aspergillus flavus," Applied Microbiology and Biotechnology, vol. 102, no. 15, pp. 6659-6672, 2018.

[12] S. Galappathie, D. J. Edwards, A. G. Elliott et al., "Antibacterial nerol cinnamates from the australian plant Eremophila longifolia," Journal of Natural Products, vol. 80, no. 4, pp. 1178-1181, 2017.

[13] K.-G. Fahlbusch, F.-J. Hammerschmidt, J. Panten et al., "Flavors and fragrances," in Ullmann's Encyclopedia of Industrial Chemistry, American Cancer Society, 2003.

[14] C. Stevensen, "The psychophysiological effects of aromatherapy massage following cardiac surgery," Complementary Therapies in Medicine, vol. 2, no. 1, pp. 27-35, 1994. 
[15] O. P. Hamill, A. Marty, E. Neher, B. Sakmann, and F. J. Sigworth, "Improved patch-clamp techniques for high-resolution current recording from cells and cell-free membrane patches," Pflügers Archiv - European Journal of Physiology, vol. 391, no. 2, pp. 85100, 1981.

[16] M. S. Santos, E. D. Oliveira, A. Santos-Miranda et al., "Dissection of the effects of quercetin on mouse myocardium," Basic \& Clinical Pharmacology \& Toxicology, vol. 120, no. 6, pp. 550-559, 2017.

[17] T. Shioya, "A simple technique for isolating healthy heart cells from mouse models," The Journal of Physiological Sciences, vol. 57, no. 6, pp. 327-335, 2007.

[18] A. Bakhtiarian, M.-J. Hosseini, A. Pousti, R. Behzadmehr, S. Sabzeh-Khah, and F. Najar, "Effect of N6-cyclopentyladenosine on ouabain-induced toxicity in isolated guinea pig atria," Toxicology Mechanisms and Methods, vol. 18, no. 7, pp. 581-583, 2008.

[19] G. P. Thomas and P. M. Stephen, "Protective action of clonidine against the arrhythmogenic and lethal effects of ouabain in guinea-pigs," British Journal of Pharmacology, vol. 104, no. 4, pp. 995-999, 1991.

[20] K. Mohammadi, L. Liu, J. Tian, P. Kometiani, Z. Xie, and A. Askari, "Positive inotropic effect of ouabain on isolated heart is accompanied by activation of signal pathways that link $\mathrm{Na}+/ \mathrm{K}+$-ATPase to ERK1/2," Journal of Cardiovascular Pharmacology, vol. 41, no. 4, pp. 609-614, 2003.

[21] M. J. Curtis and M. J. A. Walker, "Quantification of arrhythmias using scoring systems: an examination of seven scores in an in vivo model of regional myocardial ischaemia," Cardiovascular Research, vol. 22, no. 9, pp. 656-665, 1988.

[22] J. B. Shen, B. Jiang, and A. J. Pappano, "Comparison of L-type calcium channel blockade by nifedipine and/or cadmium in guinea pig ventricular myocytes," Journal of Pharmacology and Experimental Therapeutics, vol. 294, no. 2, pp. 562-570, 2000.

[23] G. Ma, W. J. Brady, M. Pollack, and T. C. Chan, "Electrocardiographic manifestations: digitalis toxicity," The Journal of Emergency Medicine, vol. 20, no. 2, pp. 145-152, 2001.

[24] T. J. Campbell and P. S. MacDonald, "Digoxin in heart failure and cardiac arrhythmias," The Medical Journal of Australia, vol. 179, no. 2, pp. 98-102, 2003.

[25] E. J. Benjamin, M. J. Blaha, S. E. Chiuve et al., "Heart disease and stroke statistics-2017 Update," Circulation, vol. 135, no. 10, pp. e146-e603, 2017.

[26] G. Monnerat, M. L. Alarcón, L. R. Vasconcellos et al., "Macrophage-dependent IL-1 $\beta$ production induces cardiac arrhythmias in diabetic mice," Nature Communications, vol. 7, no. 1, p. 13344, 2016.

[27] R. M. D. Britto, J. A. D. Silva-Neto, T. R. R. Mesquita et al., "Myrtenol protects against myocardial ischemia-reperfusion injury through antioxidant and anti-apoptotic dependent mechanisms," Food and Chemical Toxicology, vol. 111, pp. 557566, 2018.

[28] J. Li, D. Hu, X. Song, T. Han, Y. Gao, and Y. Xing, “The role of biologically active ingredients from natural drug treatments for arrhythmias in different mechanisms," BioMed Research International, vol. 2017, Article ID 4615727, 10 pages, 2017.

[29] M. Cho, I. So, J. N. Chun, and J.-H. Jeon, "The antitumor effects of geraniol: Modulation of cancer hallmark pathways (Review)," International Journal of Oncology, vol. 48, no. 5, pp. 1772-1782, 2016.

[30] B. Pavan, A. Dalpiaz, L. Marani et al., "Geraniol pharmacokinetics, bioavailability and its multiple effects on the liver antioxidant and xenobiotic-metabolizing enzymes," Frontiers in Pharmacology, vol. 9, 2018.

[31] C. M. L. Vasconcelos, I. S. N. Oliveira, J. N. A. Santos et al., "Negative inotropism of terpenes on guinea pig left atrium: structure-activity relationships," Natural Product Research, vol. 32, no. 12, pp. 1428-1431, 2018.

[32] T. Banyasz, B. Horvath, Z. Jian, L. T. Izu, and C.-I. Ye, "Profile of L-type $\mathrm{Ca} 2+$ current and $\mathrm{Na}+/ \mathrm{Ca} 2+$ exchange current during cardiac action potential in ventricular myocytes," Heart Rhythm, vol. 9, no. 1, pp. 134-142, 2012.

[33] I. Prassas and E. P. Diamandis, "Novel therapeutic applications of cardiac glycosides," Nature Reviews Drug Discovery, vol. 7, no. 11, pp. 926-935, 2008.

[34] S. Chen and S. Li, "The $\mathrm{Na} / \mathrm{Ca} 2+$ exchanger in cardiac ischemia/reperfusion injury," Medical Science Monitor, vol. 18, no. 11, pp. RA161-RA165, 2012.

[35] L. Chu, J. L. Greenstein, and R. L. Winslow, "Modeling $\mathrm{Na}^{+}-$ $\mathrm{Ca}^{2+}$ exchange in the heart: allosteric activation, spatial localization, sparks and excitation-contraction coupling," Journal of Molecular and Cellular Cardiology, vol. 99, pp. 174-187, 2016.

[36] P. Camacho, H. Fan, Z. Liu, and J. Q. He, "Small mammalian animal models of heart disease," American Journal of Cardiovascular Disease, vol. 6, pp. 70-80, 2016.

[37] D. M. Bers, "Cardiac excitation-contraction coupling," Nature, vol. 415, no. 6868, pp. 198-205, 2002. 


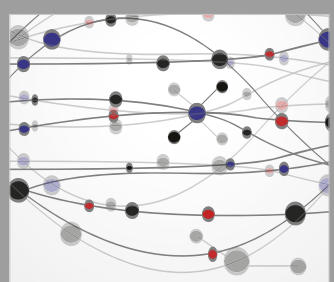

The Scientific World Journal
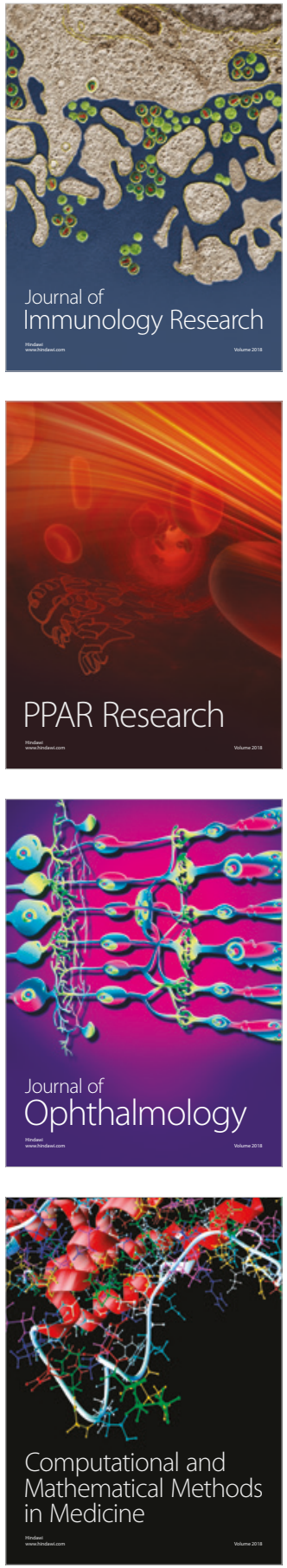

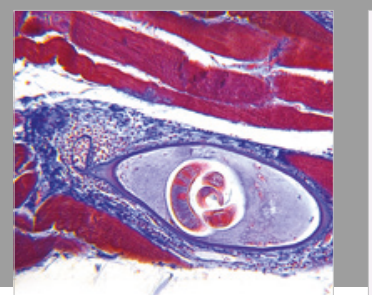

Gastroenterology Research and Practice

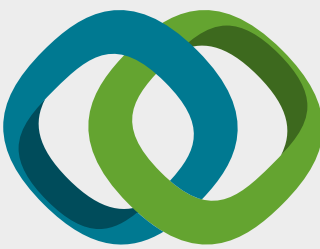

\section{Hindawi}

Submit your manuscripts at

www.hindawi.com
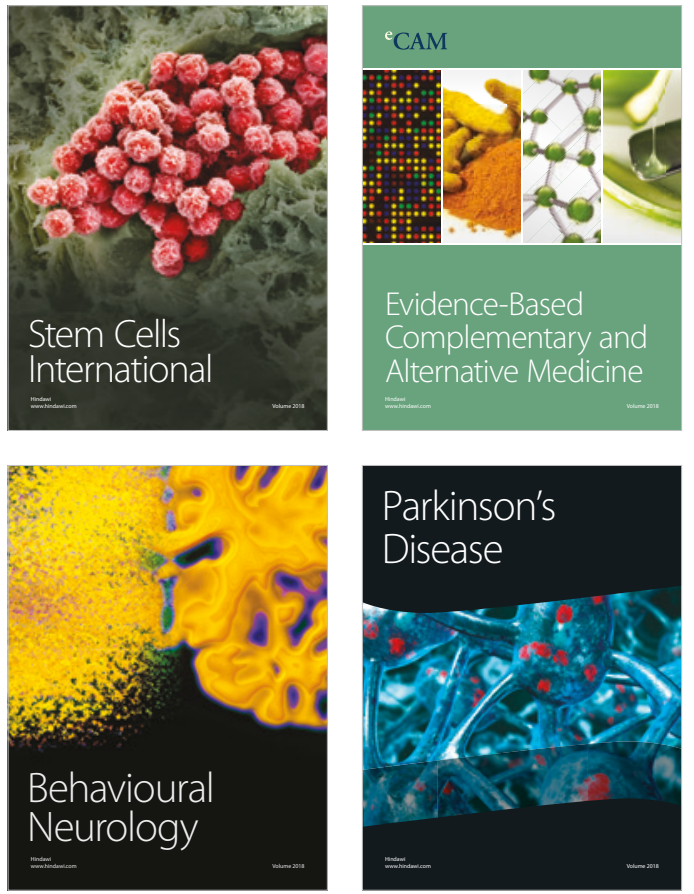

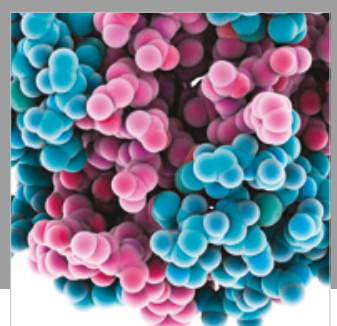

ournal of

Diabetes Research

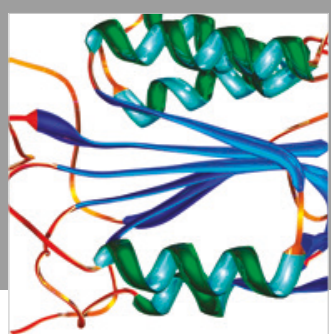

Disease Markers
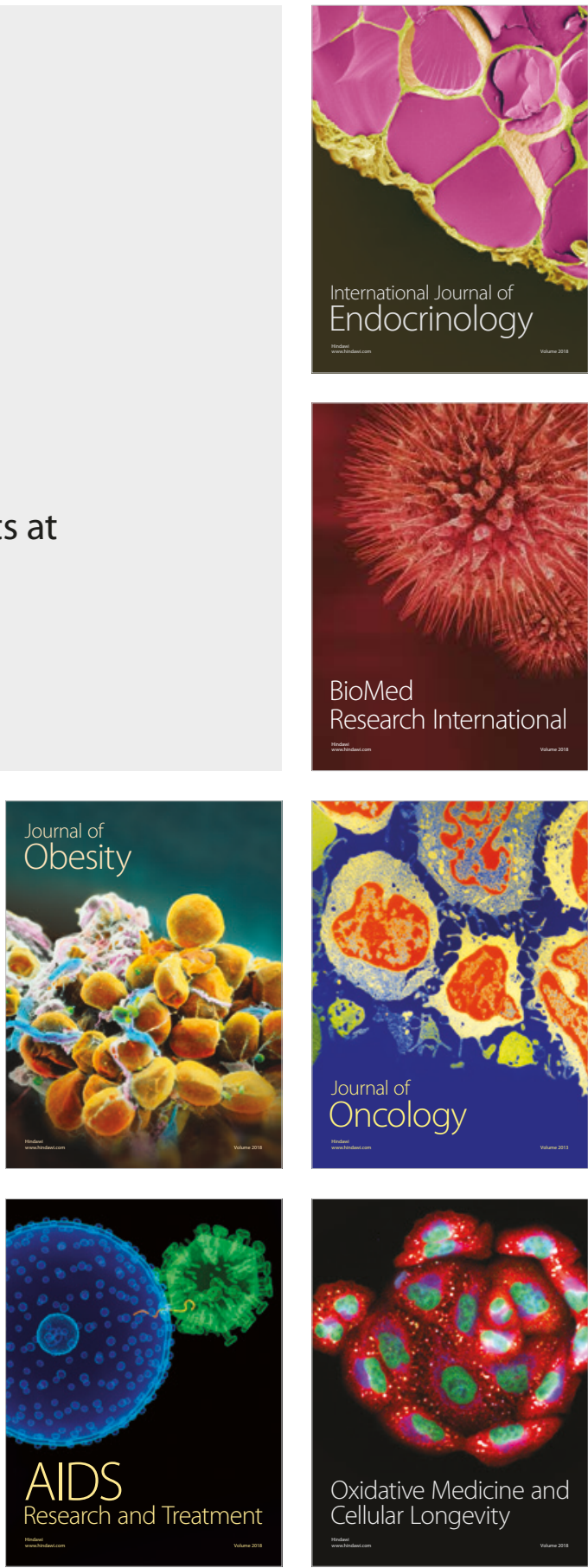